\title{
Role of Radiotherapy in the Treatment of Hepatocellular Carcinoma
}

\author{
Chien Pong Chen* \\ Department of Radiation Oncology, Scripps MD Anderson Cancer Center, San Diego, CA, USA
}

\begin{abstract}
The role of radiotherapy in the treatment of hepatocellular carcinoma (HCC) has evolved over the past few decades with the advancement of technology and improved imaging. Radiotherapy can offer high local control rates in unresectable HCC, including cases with major vascular involvement, and can provide a modality to help bridge patients to potentially curative resection or transplantation. In metastatic cases, radiotherapy can provide good palliation. This review focuses on the common radiotherapy treatment modalities used for HCC, provides outcome comparisons of these radiotherapy techniques to outcomes with other treatment modalities for $\mathrm{HCC}$, and highlights the discrepancy of the role of radiotherapy in HCC amongst the current available treatment guidelines.

Citation of this article: Chen CP. Role of radiotherapy in the treatment of hepatocellular carcinoma. J Clin Transl Hepatol 2019;7(2):183-190. doi: 10.14218/JCTH.2018.00060.
\end{abstract}

\section{Introduction}

In 2018, liver cancer is the second leading cause of cancer death in men and sixth leading cause of cancer death in women. Liver cancer is also the seventh most commonincident cancer worldwide. ${ }^{1}$ The most common type of primary liver cancer globally is hepatocellular carcinoma (HCC). In many cases, HCC arises from underlying endstage liver disease secondary to viral hepatitis or non-viral chronic liver diseases. The leading viral causes of HCC are hepatitis $B$ virus and hepatitis $C$ virus. The most common non-viral etiologies are alcohol use and non-alcoholic fatty liver disease/non-alcoholic steatohepatitis. ${ }^{2,3}$ Despite the practice of primary prevention strategies and available antiviral treatments, cases of liver cancer and HCC are expected to increase. Finding effective treatments will be imperative.

Patients with limited tumor are eligible for curative treatments, including liver transplantation. However, liver transplantation is limited by various factors including availability of

Keywords: Hepatocellular carcinoma; Liver cancer; radiotherapy; Radiation; Stereotactic body radiotherapy.

Abbreviations: 3DCRT, three-dimensional conformal radiotherapy; EBRT, external beam radiation therapy; HCC, hepatocellular carcinoma; IMRT, intensity modulated radiotherapy; MWA, microwave ablation; PBT, proton beam therapy; PVTT, portal vein tumor thrombosis; RFA, radiofrequency ablation; RILD, radiationinduced liver disease; SBRT, stereotactic body radiotherapy; SIRT, selective internal radiation therapy; TACE, trans-arterial chemoembolization.

Received: 1 December 2018; Revised: 27 April 2019; Accepted: 8 May 2019

*Correspondence to: Chien Pong Chen, Department of Radiation Oncology, Scripps MD Anderson Cancer Center, 10670 John Jay Hopkins Drive, San Diego, CA 92121, USA. Tel: +1-858-554-4100, E-mail: chen.chienpong@scrippshealth.org donor organs and strict criteria of liver transplantation for HCC patients. Other surgical options including surgical resection and novel surgical techniques to increase the available pool of organs for liver transplantation are reviewed elsewhere. ${ }^{4,5}$

A significant proportion of HCC patients are not eligible for curative treatments. Few systemic therapy options were available prior to the introduction of sorafenib. Sorafenib is currently the standard of care for patients with advanced HCC. In the SHARP and Asia-Pacific trials, sorafenib provided a survival benefit of about 2-3 months over the placebo group. ${ }^{6,7}$ However, over the past 2 years, multiple molecular-targeted agents, including regorafenib, lenvatinib, cabozantinib and ramucirumab, offer alternative or additional options to sorafenib. ${ }^{8}$ The REFLECT trial demonstrated noninferiority of lenvatinib to sorafenib as a first-line agent for $\mathrm{HCC}^{9}$ The RESORCE trial and CELESTIAL trials established the role of regorafenib and cabozantinib as second-line agents for patients refractory to sorafenib. ${ }^{10,11}$ The REACH-2 trial validated the role of ramucirumab as a second-line treatment of advanced HCC. ${ }^{12}$ Additionally, immune checkpoint modulators, such as nivolumab and pembrolizumab, have shown activity and efficacy in other malignancies and are now under investigation for HCC. ${ }^{13,14}$

As systemic therapies improve, local therapies have become more relevant and effective, even in advanced HCC cases. Local therapies that can help bridge patients to transplantation or offer palliative treatments include minimally invasive procedures, such as trans-arterial chemoembolization (TACE), radiofrequency ablation (RFA), microwave ablation (MWA), highly-focused ultrasound, and irreversible electroporation. These techniques are most effective in nodules less than $3 \mathrm{~cm}$ in diameter and can offer response rates greater than $80 \%{ }^{4}$ With that said, more recent studies indicate that MWA has several advantages, including higher thermal efficiency, faster ablation time, less severe heat sink effect, and larger ablation zones compared to RFA. MWA can safely and effectively treat larger nodules, including those up to $8 \mathrm{~cm}$ in size. ${ }^{15}$ When combined with effective systemic therapy, local therapies can offer improved outcomes than local therapies used alone. Evidence of this includes the TACTICS trial which demonstrated an increased progression-free survival with TACE plus sorafenib versus TACE alone. ${ }^{16}$

However, for locally advanced cases, minimally invasive procedures have limitations. For example, contraindications for TACE include impaired portal-vein blood flow due to portal-vein thrombus, malignant portal vein thrombosis, untreatable arteriovenous fistula, and impaired renal function. ${ }^{17,18}$ RFA and MWA are contraindicated in patients with bleeding diathesis and can be difficult in tumors close to the diaphragm, gastrointestinal tract, pancreas, hepatic hilum, and major bile ducts or vessels. ${ }^{19-21}$ Another local therapy 
that has shown promise either alone or in combination with both local and systemic therapies is radiotherapy. Various technological advances have allowed for more precise and dose escalated treatment regimens using radiotherapy. In this review, we will discuss the role of radiotherapy in HCC.

\section{Results}

\section{Conventional external beam radiation (EBRT)}

Historically, external beam radiation therapy (EBRT) has had a limited role in treating malignant hepatic tumors due to risk of radiation-induced liver disease (RILD). "Classic" RILD typically occurs within 4 months following hepatic radiation therapy and patients can present with fatigue, anicteric ascites, and hepatomegaly with relatively normal liver function tests and normal bilirubin. "Non-classic" RILD can occur within 3 months of hepatic radiation with associated jaundice and/or significant elevation of serum transaminases. Patients with underlying liver disease, such as in patients with ChildPugh score of B or C, are at higher risk for RILD that can manifest in a non-classic pattern. ${ }^{22}$ Some early work on whole liver tolerance was from treatment of liver metastases in the RTOG 76-09 and RTOG 84-05 trials. The whole liver could be safely treated to $2100 \mathrm{cGy}$ in seven fractions with daily fractionation or $3000 \mathrm{cGy}$ in twenty fractions delivered b.i.d. ${ }^{23,24}$ With these lower radiation dose regimens, EBRT only offered palliation.

However, partial liver treatment has provided insights to further dose escalation. Partial liver tolerance analysis from heavy ion treatments indicated that liver doses in excess of $3000-3500$ cGE should be limited to $30 \%$ of the liver. ${ }^{25}$ In 1991, Emami and co-workers suggested baseline partial liver tolerances. The whole liver radiation dose associated with a $5 \%$ risk of RILD is 3000 cGy, whereas a dose of 5000 cGy to $1 / 3$ of the liver is associated with the same $5 \%$ risk of RILD. ${ }^{26}$ Models for RILD were developed and demonstrated that doses as high as 7260 cGy were safe, if delivered to less than a third of the liver volume. Normal Tissue Complication Probability modeling showed that for primary hepatobiliary or liver metastases, mean dose of 5660 cGy (range 4050 cGy to $8100 \mathrm{cGy}$ ) was associated with a RILD complication rate of about $5 \%$. Further model analysis demonstrated that a dose of 3200 cGy to the whole liver was associated with $5 \%$ risk of RILD, with no cases of RILD observed when the mean dose was less than $3100 \mathrm{cGy}$. Additionally, the liver radiation tolerance was lower with patients with HCC ( $5 \%$ risk of RILD with mean liver dose of 2800 cGy at 200 cGy per fraction) versus those with liver metastases (5\% risk of RILD with mean liver dose of 3200 cGy at 200 cGy per fraction). ${ }^{27-30}$ These studies have suggested that more focal radiation approaches, such as three-dimensional conformal radiotherapy (3DCRT) and intensity modulated radiotherapy (IMRT), could offer local disease control with relatively low risk for RILD.

IMRT and 3DCRT are conventional EBRT radiation techniques that deliver optimized dose distributions in fractionated radiotherapy regimens. Both techniques utilize 3D images obtained by computed tomography to allow for target and avoidance structure, such as the normal liver tissue, delineation during radiation planning. IMRT is a more advanced EBRT technique than 3DCRT in that it uses modulated beams that allow for more improved target coverage, more conformal radiation dose distribution, and better radiation dose sparing of critical normal structures other than the liver. The main potential weakness is that IMRT may not spare as much normal liver in cases with large liver tumors greater than $6-8 \mathrm{~cm} .{ }^{31,32}$ Clinical studies comparing 3DCRT to IMRT for the treatment of HCC, which have included BCLC C or JIS Stage III and IVA patients, demonstrated higher local control and overall survival rates with IMRT. The radiation doses delivered ranged from 36006000 cGy at 180-500 cGy per fraction for 3DCRT and 40006600 cGy in 250-400 cGy per fraction for IMRT. Local control rates were $43 \%$ at 1 year and $28 \%$ at 3 years for 3DCRT and were $70 \%$ at 1 year and $47 \%$ at 3 years for IMRT, respectively. Overall survival for 3DCRT was $36 \%$ at 1 year and $14 \%$ at 3 years and for IMRT was $59 \%$ at 1 year and 33\% at 3 years. Toxicity rates were similar between 3DCRT and IMRT, with RILD rates in $5 \%$ or less of patients. ${ }^{33,34}$ Hence, these findings suggest the superiority of IMRT over 3DCRT in most cases.

Several recent studies have further demonstrated the efficacy of EBRT for definitive treatments as well as in the palliative setting. These studies included HCC patients with Child-Pugh class B and with portal vein tumor thrombosis (PVTT). Radiation doses ranged from 3000-7180 cGy in 180600 cGy per daily fraction. Some of the studies allowed combined treatments, such as TACE or concurrent chemotherapy with capecitabine. Median follow-up ranged from 5-17 months. The objective relative response ranged from $43-74 \%$, and the overall survival rate at 1 year ranged from $45-86 \%$ and at 2 years ranged from 23-69\%. Grade 3 hepatotoxicity was observed in $0-13 \%$. Combined treatments tended to increase severe toxicity with two fatalities, one of which occurred when IMRT was combined with TACE and the other when IMRT was combined with concurrent hepatic arterial infusion chemotherapy. ${ }^{35-42}$ Additionally, although rare, EBRT can be effective for HCC accompanied by inferior vena cava invasion. A recent meta-analysis showed a pooled relative response of $59 \%$ with 2 year overall survival of $37 \% .{ }^{43}$ As for palliation, radiation can palliate symptoms from bone metastases and even lymph node metastases with response rates above $73 \%$. ${ }^{44-47}$

Due to the promising results of EBRT, there is recent interest in adjuvant radiation. For curative resectable or transplantable cases, recurrence rates can be as high as $30 \% .^{48-51}$ Microvascular invasion is one factor that reduces disease-free and overall survival. ${ }^{52}$ Interestingly, postoperative adjuvant radiotherapy may be beneficial in select scenarios. In posthepatectomy patients with tumors close to major vessels and having close margins $(<1 \mathrm{~cm})$, adjuvant radiation significantly improved 3 year overall survival compared to that in patients who had close margin but did not receive radiation (overall survival $64 \%$ vs. $52 \%$ ). The results of the adjuvant radiation group were comparable to results in patients who received wide margins $(>1 \mathrm{~cm}) .{ }^{53}$ Similarly, HCC patients with microvascular invasion receiving adjuvant radiation had improved relapse-free survival and overall survival compared to TACE or conservative management. The 3 year relapse-free survival for the adjuvant radiation, adjuvant TACE, and conservative management groups were $45 \%, 27 \%$, and $11 \%$, respectively. The 3 year overall survival for the adjuvant radiation, adjuvant TACE, and conservative management groups were $73 \%, 44 \%$, and $28 \%$, respectively. ${ }^{54}$ Hence, EBRT has a role in select adjuvant settings for HCC patients.

Novel approaches using EBRT are also focusing on the role of dose-escalated regimens and combining EBRT with other therapies in advanced $\mathrm{HCC}$ cases. A recent study used a simultaneous integrated boost approach, whereby different target volumes are delineated and each target volume is 
treated simultaneously to different doses. A planning target volume 1 and 2 were created for each patient. The planning target volume 1 and 2 were treated to 5500 cGy and 4400 cGy, respectively, in 22 fractions for the low-dose group. The high-dose group received 6600 cGy and 5500 cGy to planning target volume 1 and 2, respectively. Patients in the high-dose group achieved higher objective relative response $(100 \%$ vs. $62 \%, p=0.039)$, local control at 2 years ( $86 \%$ vs. $59 \%$, $p=0.119)$, and overall survival at 2 years ( $83 \%$ vs. $44 \%$, $p=0.037) .{ }^{55}$ For locally advanced HCC, IMRT is combined with sorafenib in a phase II trial for unresectable HCC with or without PVTT. Radiation dose ranged from 4000-6000 cGy using 200 cGy per daily fraction. The 2 year overall survival rate was $32 \% .{ }^{56}$ Additionally, for unresectable HCCs, including those with PVTT, a combination of TACE and EBRT yielded improved outcomes compared to TACE alone. A meta-analysis of 25 trials demonstrated that TACE plus EBRT had a 1 year survival odds ratio of 1.36 and complete response odds ratio of 2.73 compared with TACE alone. The survival benefit was even higher at 5 years, with a 5 year odds ratio of $3.98 \mathrm{com}-$ pared to TACE alone. However, there was increased risk for gastroduodenal ulcers in the TACE plus EBRT group, with an odds ratio of $12.8 . .^{57}$

Overall, EBRT, either alone or when combined with other treatments, can offer good local control in unresectable HCC, including those with major vascular involvement, and can provide a modality to help bridge patients to potentially curative resection or transplantation. In metastatic cases, EBRT can offer good palliation.

\section{Stereotactic body radiation (SBRT)}

SBRT is an EBRT technique whereby very high, potentially ablative doses are delivered to tumors in shorter durations than for conventional EBRT. SBRT may offer higher local control rates but also require advanced tumor tracking, image guidance, and respiratory management to minimize the risk of morbidity. ${ }^{58-60}$

Recently, a number of retrospective and a few prospective studies have revealed the efficacy of SBRT as a locallyablative modality for HCC, as shown in Table 1 . Most of the studies included patients predominantly with stage I-III (TNM) or BCLC A-B patients with a minority of patients with $\mathrm{BCLC} C$ stage. A large meta-analysis demonstrated that the pooled local control for SBRT was $87 \%$ and the 1 year overall survival was $80 \%$. The pooled late toxicity rate was $6 \%{ }^{61}$ More recently, SBRT was used as a bridge to transplantation in early stage inoperable HCC, with doses ranging from 30005400 cGy using a median fractional dose of 600 cGy. Median follow-up was 12 months. Post-SBRT liver explant revealed $27 \%$ complete response, $54 \%$ partial response, and $18 \%$ stable disease. ${ }^{62}$ For HCC not eligible for transplant, SBRT can offer high rates of local control with radiographic freedom from progression of $80 \%$ with 3 year overall survival of $21 \%$. Grade 3 toxicity was noted in $8 \%$ of the patients. ${ }^{63}$

In another recent study, SBRT delivered to HCCs involved 3750-4000 cGy at 800-1250 cGy per fraction. A little more than half $(56 \%)$ of the $\mathrm{HCC}$ patients received combination TACE plus SBRT, whereas the rest received SBRT alone. This yielded a 1-year local control rate of $92 \% .{ }^{64}$ Of note, the addition of TACE to SBRT alone may not contribute much to local control or progression-free survival, especially for small HCCs. For small HCCs ineligible for resection or ablation, SBRT with or without TACE was examined. The 2 year overall survival and progression-free survival rates for the SBRT alone and SBRT plus TACE were $79 \%$ versus $80 \%$ and $49 \%$ versus $43 \%$. ${ }^{65}$ Overall, SBRT alone or in combination with other treatments can offer high control rates that are higher than conventional EBRT techniques.

When compared to other minimally invasive procedures, SBRT offers at least comparable if not more favorable efficacy profiles. Table 2 highlights the recent studies comparing the efficacy of SBRT versus other local treatments for stage I-III or BCLC A or B HCC patients. As a modality to bridging patients to transplantation, SBRT, TACE, and RFA had comparable outcomes in regards to the 5 year actuarial survival. ${ }^{66}$ In a retrospective study of inoperable HCC patients, SBRT was compared to RFA. The SBRT group had lower pretreatment Child-Pugh scores, higher pretreatment alpha-fetoprotein levels, and greater number of prior liver-directed treatments. Despite this, SBRT provided a 2 year freedom from local progression of $97 \%$ compared to $84 \%$ for RFA. Larger tumor size was a predictor for freedom from local progression for RFA but not with SBRT. The acute grade 3 or higher complication rate was $5 \%$ versus $11 \%$ for SBRT versus RFA, respectively. The overall survival at 2 years was $46 \%$ versus $53 \%$ for SBRT versus RFA, respectively. ${ }^{67}$ Similarly, after propensity score matching, the LC rate in HCC patients receiving TACE versus SBRT was comparable for local control, overall survival, and 1 year mortality. ${ }^{68}$

More recently, magnetic resonance-based strategies can offer improved assessment of SBRT treatment accuracy and can improve SBRT targeting. Gadolinium ethoxybenzyl diethylenetriaminepentaacetic acid (Gd-EOB-DTPA)-enhanced magnetic resonance images can visualize hepatic parenchymal changes. Post-SBRT Ge-EOB-DTPA-enhanced imaging can facilitate assessment of treatment accuracy. ${ }^{69}$ As for real-time target tracking, magnetic resonance-linear accelerators (known also as MR-linacs) couple a magnetic resonance imaging scanner with a linear accelerator. The magnetic resonance-linacs can potentially track and visualize tumors in real time. Since magnetic resonance images can often better delineate HCCs compared to traditional computed tomography-based images, with real-time tracking, tumor margins used for radiation planning can be minimized. With smaller margins, magnetic resonance-linac-based radiation plans could offer lower doses to organs at risk and allow for dose escalation, which can lead to higher local control rates. In a recent multiinstitutional study, magnetic resonanceguided liver SBRT was performed using a median delivered dose of $5000 \mathrm{cGy}$ in 5 fractions. With a median follow-up of 21.2 months, the freedom from local progression was $100 \%$ for HCC. No grade 4 or greater gastrointestinal toxicities were observed. ${ }^{70-72}$ SBRT, especially magnetic resonance-based SBRT, may help expand the role of radiotherapy in HCC treatment.

\section{Particle therapy}

Charged particle therapy, such as proton beam therapy (PBT) or carbon ion therapy, offers potential dosimetric advantages over conventional EBRT techniques. Charged particles have a finite range dependent upon the initial charged particle energy. For PBT, a large retrospective series of HCCs treated with hypofractionated regimens ranging from 5000-8400 cCGE using 350-500 cCGE per fraction demonstrated 5 year local control of $87 \%$ with 5 -year OS of $23 \% .^{73}$ In another study of PBT for unresectable HCC, PBT offered 2-year local control was $75 \%$ with 2 year overall survival of $55 \% .{ }^{74}$ As for 


\begin{tabular}{|c|c|c|c|c|c|c|}
\hline Study & $n$ & Stage & $\mathrm{CP}$ & SBRT details & Outcomes & $\begin{array}{l}\text { Toxicities of } \\
\text { grade } 3+\end{array}$ \\
\hline $\begin{array}{l}\text { Bujold et al. }{ }^{93} \\
(2013 \text { ) } \\
\text { Prospective } \\
\text { (phase I/II) }\end{array}$ & 102 & $\begin{array}{l}\text { BCLC A/B } \\
34 \% \\
\text { BCLC C } 66 \%\end{array}$ & $\begin{array}{l}A \\
100 \%\end{array}$ & $\begin{array}{l}\text { Median } 36 \text { Gy in } \\
6 \text { fractions }\end{array}$ & Median OS 17m & $30 \%$ \\
\hline $\begin{array}{l}\text { Culleton et al. }{ }^{94} \\
\text { (2014) } \\
\text { Prospective }\end{array}$ & 29 & $\begin{array}{l}\text { BCLC B } 7 \% \\
\text { BCLC C/D } \\
93 \%\end{array}$ & $\begin{array}{l}\text { B } 96 \% \\
\text { C } 4 \%\end{array}$ & $\begin{array}{l}30 \text { Gy in } 6 \\
\text { fractions }\end{array}$ & $\begin{array}{l}\text { 1y LC } 87 \% \\
1 y \text { OS } 55 \%\end{array}$ & $\begin{array}{l}63 \% \text { decline in } \\
\text { CP score by } \\
>=2\end{array}$ \\
\hline $\begin{array}{l}\text { Lasley et al. }{ }^{95} \\
\text { (2015) } \\
\text { Prospective }\end{array}$ & 59 & $\begin{array}{l}\text { TNM stage: } \\
\text { I } 80 \% \\
\text { II } 10 \% \\
\text { III } 3 \%\end{array}$ & $\begin{array}{l}\text { A } 64 \% \\
\text { B } 36 \%\end{array}$ & $\begin{array}{l}48 \text { Gy in } 3 \\
\text { fractions (CP A) } \\
40 \text { Gy in } 5 \\
\text { fractions (CP B) }\end{array}$ & $\begin{array}{l}\text { CP A } 2 \text { y LC } 91 \%, 3 y \text { OS } \\
61 \% \text {, median OS } 45 \mathrm{~m} \\
\text { CP B } 2 \text { y LC } 82 \%, 3 y \text { OS } \\
26 \% \text {, median OS } 17 \mathrm{~m}\end{array}$ & $\begin{array}{l}\text { CP A } 11 \% \\
\text { CP B } 38 \%\end{array}$ \\
\hline $\begin{array}{l}\text { Kang et al. }{ }^{96} \\
(2012) \\
\text { Prospective } \\
\text { (phase II) }\end{array}$ & 47 & $\begin{array}{l}\text { BCLC A } 17 \% \\
\text { BCLC B } 66 \% \\
\text { BCLC C } 17 \%\end{array}$ & $\begin{array}{l}\text { A } 87 \% \\
\text { B } 13 \%\end{array}$ & $\begin{array}{l}\text { Median } 57 \text { Gy in } \\
3 \text { fractions } \\
\text { (range } 42-60 \\
\text { Gy) }\end{array}$ & $\begin{array}{l}2 y \text { LC } 95 \% \\
2 y \text { OS } 69 \% \\
\text { CR by } 6 m 38 \%, \text { PR } 38 \%\end{array}$ & $6 \%$ \\
\hline $\begin{array}{l}\text { Sanuki et al. }{ }^{97} \\
(2014)\end{array}$ & 185 & $\begin{array}{l}\text { TNM stage: } \\
\text { I } 84 \% \\
\text { II } 11 \% \\
\text { III } 4 \%\end{array}$ & $\begin{array}{l}\text { A } 85 \% \\
\text { B } 15 \%\end{array}$ & $\begin{array}{l}\text { CP A } 40 \text { Gy in } 5 \\
\text { fractions } \\
\text { CP B } 35 \text { Gy in } 5 \\
\text { fractions }\end{array}$ & $\begin{array}{l}3 y \text { LC } 91 \% \\
3 y \text { OS } 70 \%\end{array}$ & $\begin{array}{l}13 \% \\
1 \% \text { grade } 5 \\
\text { liver failure }\end{array}$ \\
\hline $\begin{array}{l}\text { Jang et al. } 98 \\
(2013)\end{array}$ & 82 & $\begin{array}{l}\text { BCLC A } 52 \% \\
\text { BCLC B } 29 \% \\
\text { BCLC C } 18 \%\end{array}$ & $\begin{array}{l}\text { A } 90 \% \\
\text { B } 10 \%\end{array}$ & $\begin{array}{l}\text { Median } 51 \text { Gy in } \\
3 \text { fractions }\end{array}$ & $\begin{array}{l}2 y \text { LC } 87 \% \\
2 y \text { OS } 63 \%\end{array}$ & $3 \%$ \\
\hline $\begin{array}{l}\text { Yoon et al. }{ }^{99} \\
(2013)\end{array}$ & 93 & NR & $\begin{array}{l}\text { A } 74 \% \\
\text { B } 26 \%\end{array}$ & $\begin{array}{l}\text { Median } 45 \text { Gy } \\
\text { (range } 30-60 \\
\text { Gy in 3-4 } \\
\text { fractions) }\end{array}$ & $\begin{array}{l}3 y \text { OS } 54 \% \\
\text { HCC }>3 \mathrm{~cm} 3 y \text { LC } 76 \% \\
\text { HCC } 2.1-3 \mathrm{~cm} 3 y \text { LC } 93 \% \\
\mathrm{HCC}<=2 \mathrm{~cm} 3 y \text { LC } \\
100 \%\end{array}$ & $6.5 \%$ \\
\hline $\begin{array}{l}\text { Yamashita et al. }{ }^{100} \\
(2015)\end{array}$ & 79 & $\begin{array}{l}\text { I } 36 \% \\
\text { II } 26 \% \\
\text { III } 9 \%\end{array}$ & $\begin{array}{l}\text { A } 85 \% \\
\text { B } 11 \% \\
\text { C } 1 \%\end{array}$ & $\begin{array}{l}\text { Mode } 45 \text { Gy } \\
\text { (range } 30-60 \\
\text { Gy in } 3-4 \\
\text { fractions) }\end{array}$ & $\begin{array}{l}2 y \operatorname{LC} 64 \% \\
2 y \text { OS } 53 \%\end{array}$ & $0 \%$ \\
\hline $\begin{array}{l}\text { Hasan et al. }{ }^{101} \\
(2017)\end{array}$ & 40 & $\begin{array}{l}\text { BCLC } 015 \% \\
\text { BCLC A } 25 \% \\
\text { BCLC B } 60 \%\end{array}$ & $\begin{array}{l}\text { A } \\
100 \%\end{array}$ & $\begin{array}{l}\text { Mean } 45 \text { Gy } \\
\text { (range } 40-50 \\
\text { Gy in } 4-5 \\
\text { fractions) }\end{array}$ & $\begin{array}{l}2 y \text { in field LC } 98 \% \\
2 y \text { intrahepatic } \\
\text { control } 62 \% \\
2 y \text { OS } 60 \% \\
\text { Path CR } 62 \%\end{array}$ & $0 \%$ \\
\hline $\begin{array}{l}\text { Moore et al. }{ }^{62} \\
(2017)\end{array}$ & 23 & $\begin{array}{l}\text { BCLC A } \\
100 \%\end{array}$ & $\begin{array}{l}\text { A } 56 \% \\
\text { B } 44 \%\end{array}$ & $\begin{array}{l}\text { Median } 54 \text { Gy in } \\
3 \text { fractions }\end{array}$ & $\begin{array}{l}\text { CR } 27 \% \text {, PR } 54 \% \text {, } \\
\text { SD } 18 \% \\
\text { Median OS not reached } \\
\text { for transplanted patients } \\
\text { Median OS } 23 \text { m for non- } \\
\text { transplanted patients }\end{array}$ & $\begin{array}{l}4 \% \text { developed } \\
\text { RILD but } \\
\text { underwent } \\
\text { successful } \\
\text { transplant }\end{array}$ \\
\hline Qiu et al. ${ }^{63}$ (2018) & 93 & $\begin{array}{l}\text { AJCC: } \\
\text { I 50\% } \\
\text { II 14\% } \\
\text { IIIA 23\% } \\
\text { IIIB 5\% } \\
\text { IV 9\% } \\
\text { CLIP: } \\
029 \% \\
126 \% \\
232 \% \\
313 \%\end{array}$ & $\begin{array}{l}\text { A } 54 \% \\
B / C \\
46 \%\end{array}$ & $\begin{array}{l}50-60 \text { Gy in } \\
5-10 \text { fractions }\end{array}$ & $\begin{array}{l}\text { CR } 1 \%, \text { PR } 35 \%, \text { SD } \\
44 \%, \text { PD } 20 \% \\
3 y \text { OS } 21 \% \\
\text { Median OS } 8.8 \mathrm{~m}\end{array}$ & $10 \%$ \\
\hline
\end{tabular}

Abbreviations: CP, Child-Pugh; CR, complete response; FFLP, freedom from local progression; HCC, hepatocellular carcinoma; LC, local control; NR, not reported; OS, overall survival; PD, progressive disease; PFS, progression-free survival; PR, partial response; SD, stable disease; SBRT, stereotactic body radiotherapy, TNM, TNM classification of malignant tumors. 
Chen C.P.: Radiotherapy for hepatocellular carcinoma

Table 2. Select studies comparing SBRT to other local liver treatments

\begin{tabular}{|c|c|c|c|c|c|c|}
\hline Study & $n$ & Stage & $\begin{array}{l}\text { Modalities } \\
\text { compared }\end{array}$ & SBRT details & Outcomes & $\begin{array}{l}\text { Toxicities of } \\
\text { grade } 3+\end{array}$ \\
\hline $\begin{array}{l}\text { Sapir } \\
\text { et al. }{ }^{102} \\
(2018)\end{array}$ & 209 & NR & SBRT vs TACE & $\begin{array}{l}\text { Median BED } \\
100 \mathrm{~Gy}\end{array}$ & $\begin{array}{l}\text { SBRT } 2 y \text { LC } 91 \% \text {, } \\
2 y \text { OS } 55 \% \\
\text { TACE } 2 y \text { LC } 23 \% \text {, } \\
2 y \text { OS } 35 \%\end{array}$ & $\begin{array}{l}\text { SBRT } 8 \% \text { vs } \\
\text { TACE } 13 \% \\
(p=0.05)\end{array}$ \\
\hline $\begin{array}{l}\text { Mohamed } \\
\text { et al. }{ }^{103} \\
(2016)\end{array}$ & 60 & $\begin{array}{l}\text { IM } 78 \% \\
\text { OM } 22 \%\end{array}$ & $\begin{array}{l}\text { SBRT vs TACE } \\
\text { vs RFA vs Y90 } \\
\text { as bridge to } \\
\text { transplant }\end{array}$ & $\begin{array}{l}\text { Median } 50 \text { Gy } \\
\text { (range } 45-60 \mathrm{~Gy} \text { ) } \\
\text { Y90 - average } \\
\text { dose } 109 \mathrm{~Gy}\end{array}$ & $\begin{array}{l}\text { SBRT PD } 4 \% \text {, NN } 14 \% \\
\text { TACE PD } 5.5 \% \text {, NN } 4 \% \\
\text { RFA PD } 0 \% \text {, NN } 20 \% \\
\text { Y90 PD } 11 \% \text {, NN } 0 \%\end{array}$ & $\begin{array}{l}\text { SBRT } 0 \% \\
\text { TACE } 11 \% \\
\text { RFA } 22 \% \\
\text { Y90 0\% }\end{array}$ \\
\hline $\begin{array}{l}\text { Wahl } \\
\text { et al. } \\
(2016)\end{array}$ & 224 & $\begin{array}{l}\text { Mostly TNM } \\
\text { Stage I/II }\end{array}$ & SBRT vs RFA & $\begin{array}{l}\text { Median BED } \\
100 \mathrm{~Gy}\end{array}$ & $\begin{array}{l}\text { SBRT } 2 \text { y FFLP } 84 \% \\
2 y \text { OS } 46 \% \\
\text { RFA } 2 \text { y FFLP } 80 \% \\
2 y \text { OS } 53 \%\end{array}$ & $\begin{array}{l}\text { SBRT } 5 \% \\
\text { RFA } 11 \%\end{array}$ \\
\hline $\begin{array}{l}\text { Su } \\
\text { et al. }{ }^{104} \\
(2017)\end{array}$ & 117 & $\begin{array}{l}\text { BCLC A } 93 \% \\
\text { BCLC B } 7 \%\end{array}$ & $\begin{array}{l}\text { SBRT vs } \\
\text { Resection }\end{array}$ & $\begin{array}{l}42-48 \text { Gy in } \\
3-5 \text { fractions }\end{array}$ & $\begin{array}{l}\text { SBRT } 5 y \text { OS } 70 \%, \\
5 y \text { PFS } 41 \% \\
\text { Resection } 5 y \text { OS } 64 \% \text {, } \\
5 y \text { PFS } 40 \%\end{array}$ & $\begin{array}{l}\text { SBRT } 3 \% \text { (nausea, } \\
\text { weight loss) } \\
\text { Resection - } 25 \% \\
\text { (hepatic pain, } \\
\text { hepatic } \\
\text { hemorrhage, } \\
\text { weight loss) }\end{array}$ \\
\hline
\end{tabular}

Abbreviations: BED, biological equivalent dose; $\mathrm{CP}$, Child-Pugh; $\mathrm{CR}$, complete response; FFLP, freedom from local progression; $\mathrm{HCC}$, hepatocellular carcinoma; IM, inside Milan; LC, local control; NN, no necrosis on pathological response; NR, not reported; OM, outside Milan; OS, overall survival; PD, progressive disease; PFS, progression-free survival; PR, partial response; SD, stable disease; RFA, radiofrequency ablation; SBRT, stereotactic body radiotherapy; TACE, transarterial chemoembolization; Y90, Yttrium-90 radioembolization.

patients with PVTT and vascular invasion, PBT can also provide 2 year overall survival rates greater than $40 \% .{ }^{75,76} \mathrm{~A}$ recent review of PBT for HCC reported 3 year local control rates of $70-$ $88 \%$ and 3 year overall survival rates ranging from $45-65 \% .{ }^{77}$ Additionally, heavy charged particles, such as carbon ion, have higher radiobiological effectiveness and linear energy transfer than conventional $\mathrm{x}$-rays or even protons. The higher radiobiological effectiveness and linear energy transfer of heavy ions can theoretically produce greater outcomes, but the use of heavy ion treatments is limited by the significant cost associated with construction and operations of such facilities. However, carbon ion therapy for HCC can offer 5 year local control rates of $81-96 \%$, with late grade 3 toxicity in the 3$4 \%$ range. ${ }^{78,79}$ More recently, a review of charged particle therapy cited actuarial local control rates ranging from 71$95 \%$ at 3 years and overall survival at 5 years ranging from $25-42 \%$. Late grade 3 or higher adverse events occurred in only $2 \%$ of patients. ${ }^{80}$ However, a meta-analysis comparing charged particles and SBRT showed that the outcomes were comparable, with no advantage in survival or local control with particle therapy. ${ }^{61}$ Charged particle therapy does provide some potential advantages over conventional EBRT techniques but further investigation is needed.

\section{Selective internal radiation therapy (SIRT)}

SIRT involves the injection of microspheres with $\beta$-emitting radioisotope, commonly 90Yttrium. SIRT has been useful in treating large lesions more than $7 \mathrm{~cm}$ in diameter and tumors with vascular invasion. Disease control rates as high as $70-80 \%$ have been achieved. ${ }^{81}$ However, adverse events including radiation pneumonitis, pulmonary fibrosis due to hepato-pulmonary shunts, post-radioembolization syndrome, which involves abdominal pain, fever, and nausea, and radioembolization-induced liver disease have been observed. ${ }^{82,83}$ Additionally, for PVTT, SIRT may not be as effective as other radiation modalities. In a recent meta-analysis of HCC with PVTT, the pooled response rate for SIRT was 33\% versus $51 \%$ for 3DCRT and $71 \%$ for SBRT. The pooled 1 year overall survival rates for SIRT, 3DCRT, and SBRT were 38\%, 44\%, and $46 \%$, respectively. ${ }^{84}$ In another recent study comparing SIRT to SBRT involving unresectable HCC, no difference was noted in overall survival or disease-specific survival. ${ }^{85}$ Hence, proper patient selection is paramount for SIRT.

\section{Conclusions}

Radiotherapy has evolved rapidly over the past two decades. With advancements in technology, including improved image guidance and dose escalation with partial liver treatments, high local control rates with relatively low toxicity have been achieved with the various radiotherapy modalities. Additionally, as systemic therapies improve, loco-regional therapies become more relevant. Multiple clinical trials utilizing EBRT alone or in combination with other treatment modalities, which include systemic or local therapies, are underway. ${ }^{86}$

Despite the evidence of the effectiveness of radiotherapy in HCC, guidelines have continued to suggest a limited role for radiation. The recently updated European Association for the Study of the Liver guidelines indicate that EBRT is under investigation and that there is no evidence to support its routine role in the management of $\mathrm{HCC}^{87}$ The American Association for the Study of Liver Disease guidelines from 2018 do cite some studies involving EBRT but overall, radiotherapy was not recommended in essentially all scenarios. ${ }^{88}$ The Japan Society of Hepatology guidelines also do not mention radiotherapy in the treatment of $\mathrm{HCC}^{89}$ The main 
reason for lack of inclusion of radiotherapy in management guidelines was the lack of randomized trials.

In contrast, the Asian Pacific Association for the Study of the Liver guidelines indicate that SBRT and charged particle therapy are reasonable options for patients who have failed other local therapies. Radiotherapy could also be considered for symptomatic bony metastases. ${ }^{90}$ The Korean Liver Cancer Society guidelines describe the best and alternative options for various clinical settings based on the modified Union for International Cancer Control staging. EBRT is indicated as options in multiple settings including Child-Pugh class $A$ or "superb $B$ " and the irradiated total liver volume receiving greater than 3000 cGy is less than $60 \%$, unresectable HCC not amenable to other local treatments, HCC patients with incomplete response to TACE when dose-volume criteria are met, HCC patients with PVTT when dose-volume criteria are met, and for palliation in metastatic HCC. ${ }^{91}$ The most liberal indications of radiotherapy occur in the guidelines in China. The Chinese guidelines suggest a potential role for radiotherapy in multiple settings including locally advanced disease with PVTT, as a bridging treatment for HCC patients awaiting transplantation, adjuvant therapy for select patients with close margins, and palliative treatment for recurrent or metastatic disease. ${ }^{92}$

With more evidence of the efficacy of radiotherapy in HCC, the updated National Comprehensive Cancer Network guidelines (version 5.2018) have included radiotherapy as a treatment modality for HCC patients that are unresectable or ineligible for transplant. Given the variability of recommendations from different guidelines, a multidisciplinary team involving hepatology, surgical oncology, medical oncology, and radiation oncology should ideally convene to make the appropriate treatment recommendations for each HCC patient.

\section{Acknowledgments}

I would like to thank my colleagues, Drs. Catherine Frenette, Ray Lin and Prabhakar Tripuraneni who have provided valuable insights that improved the manuscript.

\section{Conflict of interest}

The author has no conflict of interests related to this publication.

\section{Author contributions}

Performed the manuscript writing, critical revisions, and all administrative duties related to the preparation of this article (CPC).

\section{References}

[1] Bray F, Ferlay J, Soerjomataram I, Siegel RL, Torre LA, Jemal A. Global cancer statistics 2018: GLOBOCAN estimates of incidence and mortality worldwide for 36 cancers in 185 countries. CA Cancer J Clin 2018;68: 394-424. doi: 10.3322/caac. 21492.

[2] Akinyemiju T, Abera S, Ahmed M, Alam N, Alemayohu MA, Allen C, et al. The burden of primary liver cancer and underlying etiologies from 1990 to 2015 at the global, regional, and national level: Results from the Global Burden of Disease study 2015. JAMA Oncol 2017;3:1683-1691. doi: 10. 1001/jamaoncol.2017.3055.

[3] Younossi ZM, Koenig AB, Abdelatif D, Fazel Y, Henry L, Wymer M. Global epidemiology of nonalcoholic fatty liver disease-Meta-analytic assessment of prevalence, incidence, and outcomes. Hepatology 2016;64:73-84. doi: 10.1002/hep.28431.

[4] Daher S, Massarwa M, Benson AA, Khoury T. Current and future treatment of hepatocellular carcinoma: An updated comprehensive review. J Clin Transl Hepatol 2018;6:69-78. doi: 10.14218/JCTH.2017.00031.

[5] Sapisochin G, Bruix J. Liver transplantation for hepatocellular carcinoma: outcomes and novel surgical approaches. Nat Rev Gastroenterol Hepatol 2017;14:203-217. doi: 10.1038/nrgastro.2016.193.

[6] Cheng AL, Kang YK, Chen Z, Tsao CJ, Qin S, Kim JS, et al. Efficacy and safety of sorafenib in patients in the Asia-Pacific region with advanced hepatocellular carcinoma: a phase III randomised, double-blind, placebo-controlled trial. Lancet Oncol 2009;10:25-34. doi: 10.1016/S1470-2045(08)70285-7.

[7] Llovet JM, Ricci S, Mazzaferro V, Hilgard P, Gane E, Blanc JF, et al. Sorafenib in advanced hepatocellular carcinoma. N Engl J Med 2008;359:378-390. doi: $10.1056 /$ NEJMoa0708857.

[8] Kudo M. Systemic therapy for hepatocellular carcinoma: Latest advances. Cancers (Basel) 2018;10:E412. doi: 10.3390/cancers10110412.

[9] Kudo M, Finn RS, Qin S, Han KH, Ikeda K, Piscaglia F, et al. Lenvatinib versus sorafenib in first-line treatment of patients with unresectable hepatocellular carcinoma: a randomised phase 3 non-inferiority trial. Lancet 2018;391: 1163-1173. doi: 10.1016/S0140-6736(18)30207-1.

[10] Abou-Alfa GK, Meyer T, Cheng AL, El-Khoueiry AB, Rimassa L, Ryoo BY, et al. Cabozantinib in patients with advanced and progressing hepatocellular carcinoma. N Engl J Med 2018;379:54-63. doi: 10.1056/NEJMoa1717002.

[11] Bruix J, Qin S, Merle P, Granito A, Huang YH, Bodoky G, et al. Regorafenib for patients with hepatocellular carcinoma who progressed on sorafenib treatment (RESORCE): a randomised, double-blind, placebo-controlled, phase 3 trial. Lancet 2017;389:56-66. doi: 10.1016/S0140-6736(16)32453-9.

[12] Zhu AX, Kang YK, Yen CJ, Finn RS, Galle PR, Llovet JM, et al. REACH-2: A randomized, double-blind, placebo-controlled phase 3 study of ramucirumab versus placebo as second-line treatment in patients with advanced hepatocellular carcinoma (HCC) and elevated baseline alpha-fetoprotein (AFP) following first-line sorafenib. J Clin Oncol 2018;36:4003. doi: 10. 1200/JCO.2018.36.15_suppl.4003.

[13] Zhu AX, Finn RS, Edeline J, Cattan S, Ogasawara S, Palmer D, et al. Pembrolizumab in patients with advanced hepatocellular carcinoma previously treated with sorafenib (KEYNOTE-224): a non-randomised, open-label phase 2 trial. Lancet Oncol 2018;19:940-952. doi: 10.1016/S1470-2045 (18)30351-6

[14] El-Khoueiry AB, Sangro B, Yau T, Crocenzi TS, Kudo M, Hsu C, et al. Nivolumab in patients with advanced hepatocellular carcinoma (CheckMate 040): an open-label, non-comparative, phase $1 / 2$ dose escalation and expansion trial. Lancet 2017;389:2492-2502. doi: 10.1016/S0140-6736 (17)31046-2.

[15] Giorgio A, Gatti P, Montesarchio L, Merola MG, Amendola F, Calvanese A, et al. Microwave ablation in intermediate hepatocellular carcinoma in cirrhosis: An Italian multicenter prospective study. J Clin Transl Hepatol 2018; 6:251-257. doi: 10.14218/JCTH.2018.00013.

[16] Kudo M, Ueshima K, Ikeda M, Torimura T, Tanabe N, Aikata H, et al. Randomized, open label, multicenter, phase II trial of comparing transarterial chemoembolization (TACE) plus sorafenib with TACE alone in patients with hepatocellular carcinoma (HCC): TACTICS trial. J Clin Oncol 2018;36: 206. doi: 10.1200/JCO.2018.36.4_suppl.206.

[17] Raoul JL, Sangro B, Forner A, Mazzaferro V, Piscaglia F, Bolondi L, et al. Evolving strategies for the management of intermediate-stage hepatocellular carcinoma: available evidence and expert opinion on the use of transarterial chemoembolization. Cancer Treat Rev 2011;37:212-220. doi: 10. 1016/j.ctrv.2010.07.006.

[18] Forner A, Gilabert M, Bruix J, Raoul JL. Treatment of intermediate-stage hepatocellular carcinoma. Nat Rev Clin Oncol 2014;11:525-535. doi: 10. 1038/nrclinonc.2014.122.

[19] de Baere T, Bessoud B, Dromain C, Ducreux M, Boige V, Lassau N, et al. Percutaneous radiofrequency ablation of hepatic tumors during temporary venous occlusion. AJR Am J Roentgenol 2002;178:53-59. doi: 10.2214/ajr. 178.1.1780053.

[20] Lau WY, Leung TW, Yu SC, Ho SK. Percutaneous local ablative therapy for hepatocellular carcinoma: a review and look into the future. Ann Surg 2003; 237:171-179. doi: 10.1097/01.SLA.0000048443.71734.BF.

[21] Liang P, Yu J, Lu MD, Dong BW, Yu XL, Zhou XD, et al. Practice guidelines for ultrasound-guided percutaneous microwave ablation for hepatic malignancy. World J Gastroenterol 2013;19:5430-5438. doi: 10.3748/wjg.v19. i33.5430.

[22] Guha C, Kavanagh BD. Hepatic radiation toxicity: avoidance and amelioration. Semin Radiat Oncol 2011;21:256-263. doi: 10.1016/j.semradonc. 2011.05.003.

[23] Russell AH, Clyde $\mathrm{C}$, Wasserman TH, Turner SS, Rotman M. Accelerated hyperfractionated hepatic irradiation in the management of patients with liver metastases: results of the RTOG dose escalating protocol. Int J Radiat Oncol Biol Phys 1993;27:117-123. doi: 10.1016/0360-3016(93) 90428-X. 
[24] Borgelt BB, Gelber R, Brady LW, Griffin T, Hendrickson FR. The palliation of hepatic metastases: results of the Radiation Therapy Oncology Group pilot study. Int J Radiat Oncol Biol Phys 1981;7:587-591. doi: 10.1016/03603016(81)90370-9.

[25] Austin-Seymour MM, Chen GT, Castro JR, Saunders WM, Pitluck S, Woodruff $\mathrm{KH}$, et al. Dose volume histogram analysis of liver radiation tolerance. Int J Radiat Oncol Biol Phys 1986;12:31-35. doi: 10.1016/0360-3016(86) 90412-8.

[26] Emami B, Lyman J, Brown A, Coia L, Goitein M, Munzenrider JE, et al. Tolerance of normal tissue to therapeutic irradiation. Int J Radiat Oncol Biol Phys 1991;21:109-122. doi: 10.1016/0360-3016(91)90171-Y.

[27] Dawson LA, Ten Haken RK. Partial volume tolerance of the liver to radiation. Semin Radiat Oncol 2005;15:279-283. doi: 10.1016/j.semradonc.2005. 04.005.

[28] Dawson LA, Normolle D, Balter JM, McGinn C], Lawrence TS, Ten Haken RK. Analysis of radiation-induced liver disease using the Lyman NTCP model. Int J Radiat Oncol Biol Phys 2002;53:810-821. doi: 10.1016/S0360-3016(02) 02846-8.

[29] Robertson JM, Lawrence TS, Walker S, Kessler ML, Andrews JC, Ensminger WD. The treatment of colorectal liver metastases with conformal radiation therapy and regional chemotherapy. Int J Radiat Oncol Biol Phys 1995;32: 445-450. doi: 10.1016/0360-3016(94)00591-8.

[30] McGinn CJ, Ten Haken RK, Ensminger WD, Walker S, Wang S, Lawrence TS. Treatment of intrahepatic cancers with radiation doses based on a normal tissue complication probability model. J Clin Oncol 1998;16:2246-2252. doi: $10.1200 / J C O .1998 .16 .6 .2246$.

[31] Bae SH, Jang WI, Park HC. Intensity-modulated radiotherapy for hepatocellular carcinoma: dosimetric and clinical results. Oncotarget 2017;8:5996559976. doi: 10.18632/oncotarget.19219.

[32] Chen D, Wang R, Meng X, Liu T, Yan H, Feng R, et al. A comparison of liver protection among 3-D conformal radiotherapy, intensity-modulated radiotherapy and RapidArc for hepatocellular carcinoma. Radiat Oncol 2014;9: 48. doi: 10.1186/1748-717X-9-48.

[33] Hou JZ, Zeng ZC, Wang BL, Yang P, Zhang JY, Mo HF. High dose radiotherapy with image-guided hypo-IMRT for hepatocellular carcinoma with portal vein and/or inferior vena cava tumor thrombi is more feasible and efficacious than conventional 3D-CRT. Jpn J Clin Oncol 2016;46:357-362. doi: 10. 1093/jjco/hyv205.

[34] Yoon HI, Lee IJ, Han KH, Seong J. Improved oncologic outcomes with image-guided intensity-modulated radiation therapy using helical tomotherapy in locally advanced hepatocellular carcinoma. J Cancer Res Clin Oncol 2014;140:1595-1605. doi: 10.1007/s00432-014-1697-0.

[35] Kang MK, Kim MS, Kim SK, Ye GW, Lee HJ, Kim TN, et al. High-dose radiotherapy with intensity-modulated radiation therapy for advanced hepatocellular carcinoma. Tumori 2011;97:724-731. doi: 10.1700/1018.11088.

[36] Zhang T, Zhao YT, Wang Z, Li CR, Jin J, Jia AY, et al. Efficacy and safety of intensity-modulated radiotherapy following transarterial chemoembolization in patients with unresectable hepatocellular carcinoma. Medicine (Baltimore) 2016;95:e3789. doi: 10.1097/MD.0000000000003789.

[37] McIntosh A, Hagspiel KD, Al-Osaimi AM, Northup P, Caldwell S, Berg C, et al. Accelerated treatment using intensity-modulated radiation therapy plus concurrent capecitabine for unresectable hepatocellular carcinoma. Cancer 2009;115:5117-5125. doi: 10.1002/cncr.24552.

[38] Chi KH, Liao CS, Chang CC, Ko HL, Tsang YW, Yang KC, et al. Angiogenic blockade and radiotherapy in hepatocellular carcinoma. Int J Radiat Oncol Biol Phys 2010;78:188-193. doi: 10.1016/j.ijrobp.2009.07.1725.

[39] Kong M, Hong SE, Choi WS, Choi J, Kim Y. Treatment outcomes of helical intensity-modulated radiotherapy for unresectable hepatocellular carcinoma. Gut Liver 2013;7:343-351. doi: 10.5009/gnl.2013.7.3.343.

[40] Kim JY, Yoo EJ, Jang JW, Kwon JH, Kim KJ, Kay CS. Hypofractionated radiotheapy using helical tomotherapy for advanced hepatocellular carcinoma with portal vein tumor thrombosis. Radiat Oncol 2013;8:15. doi: 10. 1186/1748-717X-8-15.

[41] Huang CM, Huang MY, Tang JY, Chen SC, Wang LY, Lin ZY, et al. Feasibility and efficacy of helical tomotherapy in cirrhotic patients with unresectable hepatocellular carcinoma. World J Surg Oncol 2015;13:201. doi: 10. 1186/s12957-015-0611-9.

[42] Wang PM, Hsu WC, Chung NN, Chang FL, Fogliata A, Cozzi L. Radiotherapy with volumetric modulated arc therapy for hepatocellular carcinoma patients ineligible for surgery or ablative treatments. Strahlenther Onkol 2013;189:301-307. doi: 10.1007/s00066-012-0298-6.

[43] Rim CH, Kim CY, Yang DS, Yoon WS. External beam radiation therapy to hepatocellular carcinoma involving inferior vena cava and/or right atrium: A meta-analysis and systemic review. Radiother Oncol 2018;129:123-129. doi: 10.1016/j.radonc.2018.02.030.

[44] He J, Zeng ZC, Tang ZY, Fan J, Zhou J, Zeng MS, et al. Clinical features and prognostic factors in patients with bone metastases from hepatocellular carcinoma receiving external beam radiotherapy. Cancer 2009;115:27102720. doi: $10.1002 /$ cncr.24300.
[45] Hayashi S, Tanaka H, Hoshi H. Palliative external-beam radiotherapy for bone metastases from hepatocellular carcinoma. World J Hepatol 2014;6: 923-929. doi: 10.4254/wjh.v6.i12.923.

[46] Bhatia R, Ravulapati S, Befeler A, Dombrowski J, Gadani S, Poddar N. Hepatocellular carcinoma with bone metastases: Incidence, prognostic significance, and management-single-center experience. J Gastrointest Cancer 2017;48:321-325. doi: 10.1007/s12029-017-9998-6.

[47] Rim CH, Kim CY, Yang DS, Yoon WS. The role of external beam radiotherapy for hepatocellular carcinoma patients with lymph node metastasis: a metaanalysis of observational studies. Cancer Manag Res 2018;10:3305-3315. doi: 10.2147/CMAR.S175703.

[48] Lai EC, Fan ST, Lo CM, Chu KM, Liu CL, Wong J. Hepatic resection for hepatocellular carcinoma. An audit of 343 patients. Ann Surg 1995;221:291298. doi: 10.1097/00000658-199503000-00012.

[49] Schwarz RE, Smith DD. Trends in local therapy for hepatocellular carcinoma and survival outcomes in the US population. Am J Surg 2008;195:829-836. doi: 10.1016/j.amjsurg.2007.10.010.

[50] Liang W, Wu L, Ling X, Schroder PM, Ju W, Wang D, et al. Living donor liver transplantation versus deceased donor liver transplantation for hepatocelIular carcinoma: a meta-analysis. Liver Transpl 2012;18:1226-1236. doi: $10.1002 /$ It. 23490.

[51] Grant RC, Sandhu L, Dixon PR, Greig PD, Grant DR, McGilvray ID. Living vs. deceased donor liver transplantation for hepatocellular carcinoma: a systematic review and meta-analysis. Clin Transplant 2013;27:140-147. doi: 10.1111/ctr.12031.

[52] Rodríguez-Perálvarez M, Luong TV, Andreana L, Meyer T, Dhillon AP, Burroughs AK. A systematic review of microvascular invasion in hepatocellular carcinoma: diagnostic and prognostic variability. Ann Surg Oncol 2013;20: 325-339. doi: 10.1245/s10434-012-2513-1.

[53] Wang WH, Wang Z, Wu JX, Zhang T, Rong WQ, Wang LM, et al. Survival benefit with IMRT following narrow-margin hepatectomy in patients with hepatocellular carcinoma close to major vessels. Liver Int 2015;35:26032610. doi: 10.1111/liv.12857.

[54] Wang L, Wang W, Yao X, Rong W, Wu F, Chen B, et al. Postoperative adjuvant radiotherapy is associated with improved survival in hepatocellular carcinoma with microvascular invasion. Oncotarget 2017;8:79971-79981. doi: 10.18632/oncotarget.20402.

[55] Kim TH, Park JW, Kim Y], Kim BH, Woo SM, Moon SH, et al. Simultaneous integrated boost-intensity modulated radiation therapy for inoperable hepatocellular carcinoma. Strahlenther Onkol 2014;190:882-890. doi: 10. 1007/s00066-014-0643-z.

[56] Chen SW, Lin LC, Kuo YC, Liang JA, Kuo CC, Chiou JF. Phase 2 study of combined sorafenib and radiation therapy in patients with advanced hepatocellular carcinoma. Int J Radiat Oncol Biol Phys 2014;88:1041-1047. doi: 10.1016/j.ijrobp.2014.01.017.

[57] Huo YR, Eslick GD. Transcatheter arterial chemoembolization plus radiotherapy compared with chemoembolization alone for hepatocellular carcinoma: A systematic review and meta-analysis. JAMA Oncol 2015;1:756-765. doi: 10.1001/jamaoncol.2015.2189.

[58] Guckenberger M, Sweeney RA, Wilbert J, Krieger T, Richter A, Baier K, et al. Image-guided radiotherapy for liver cancer using respiratory-correlated computed tomography and cone-beam computed tomography. Int J Radiat Oncol Biol Phys 2008;71:297-304. doi: 10.1016/j.ijrobp.2008.01. 005.

[59] Kubo HD, Hill BC. Respiration gated radiotherapy treatment: a technical study. Phys Med Biol 1996;41:83-91. doi: 10.1088/0031-9155/41/1/007.

[60] Shimohigashi Y, Toya R, Saito T, Ikeda O, Maruyama M, Yonemura K, et al. Tumor motion changes in stereotactic body radiotherapy for liver tumors: an evaluation based on four-dimensional cone-beam computed tomography and fiducial markers. Radiat Oncol 2017;12:61. doi: 10.1186/s13014017-0799-7.

[61] Qi WX, Fu S, Zhang Q, Guo XM. Charged particle therapy versus photon therapy for patients with hepatocellular carcinoma: a systematic review and meta-analysis. Radiother Oncol 2015;114:289-295. doi: 10.1016/j. radonc. 2014.11.033.

[62] Moore A, Cohen-Naftaly M, Tobar A, Kundel Y, Benjaminov O, Braun M, et al. Stereotactic body radiation therapy (SBRT) for definitive treatment and as a bridge to liver transplantation in early stage inoperable hepatocellular carcinoma. Radiat Oncol 2017;12:163. doi: 10.1186/s13014-017-0899-4.

[63] Qiu H, Moravan MJ, Milano MT, Usuki KY, Katz AW. SBRT for hepatocellular carcinoma: 8-year experience from a regional transplant center. J Gastrointest Cancer 2018;49:463-469. doi: 10.1007/s12029-017-9990-1.

[64] Gerum S, Heinz C, Belka C, Walter F, Paprottka P, De Toni EN, et al. Stereotactic body radiation therapy (SBRT) in patients with hepatocellular carcinoma and oligometastatic liver disease. Radiat Oncol 2018;13:100. doi: 10. 1186/s13014-018-1048-4.

[65] Kimura T, Aikata H, Doi Y, Imano N, Takeuchi Y, Takahashi I, et al. Comparison of stereotactic body radiation therapy combined with or without transcatheter arterial chemoembolization for patients with small hepatocellular 
carcinoma ineligible for resection or ablation therapies. Technol Cancer Res Treat 2018;17:1533033818783450. doi: 10.1177/1533033818783450.

[66] Sapisochin G, Barry A, Doherty M, Fischer S, Goldaracena N, Rosales R, et al. Stereotactic body radiotherapy vs. TACE or RFA as a bridge to transplant in patients with hepatocellular carcinoma. An intention-to-treat analysis. J Hepatol 2017;67:92-99. doi: 10.1016/j.jhep.2017.02.022.

[67] Wahl DR, Stenmark MH, Tao Y, Pollom EL, Caoili EM, Lawrence TS, et al. Outcomes after stereotactic body radiotherapy or radiofrequency ablation for hepatocellular carcinoma. J Clin Oncol 2016;34:452-459. doi: 10. 1200/JCO.2015.61.4925.

[68] Bettinger D, Gkika E, Schultheiss M, Glaser N, Lange S, Maruschke L, et al. Comparison of local tumor control in patients with $\mathrm{HCC}$ treated with SBRT or TACE: a propensity score analysis. BMC Cancer 2018;18:807. doi: 10 . 1186/s12885-018-4696-8.

[69] Jung J, Kim H, Yoon SM, Cho B, Kim YJ, Kwak J, et al. Targeting accuracy of image-guided stereotactic body radiation therapy for hepatocellular carcinoma in real-life clinical practice: In vivo assessment using hepatic parenchymal changes on Gd-EOB-DTPA-enhanced magnetic resonance images. Int J Radiat Oncol Biol Phys 2018;102:867-874. doi: 10.1016/j.ijrobp. 2018.05.018.

[70] Rosenberg SA, Henke LE, Shaverdian N, Mittauer K, Wojcieszynski AP, Hullett $C R$, et al. A multi-institutional experience of MR-guided liver stereotactic body radiation therapy. Adv Radiat Oncol 2018;4:142-149. doi: 10. 1016/j.adro.2018.08.005

[71] Al-Ward S, Wronski M, Ahmad SB, Myrehaug S, Chu W, Sahgal A, et al. The radiobiological impact of motion tracking of liver, pancreas and kidney SBRT tumors in a MR-linac. Phys Med Biol 2018;63:215022. doi: 10.1088/1361$6560 / \mathrm{aae} 7 \mathrm{fd}$.

[72] Fast M, van de Schoot A, van de Lindt T, Carbaat C, van der Heide U, Sonke JJ. Tumor trailing for liver SBRT on the MR-linac. Int J Radiat Oncol Biol Phys 2019;103:468-478. doi: 10.1016/j.ijrobp.2018.09.011.

[73] Chiba T, Tokuuye K, Matsuzaki Y, Sugahara S, Chuganji Y, Kagei K, et al. Proton beam therapy for hepatocellular carcinoma: a retrospective review of 162 patients. Clin Cancer Res 2005;11:3799-3805. doi: 10.1158/10780432. CCR-04-1350.

[74] Bush DA, Hillebrand DJ, Slater JM, Slater JD. High-dose proton beam radiotherapy of hepatocellular carcinoma: preliminary results of a phase II trial. Gastroenterology 2004;127:S189-S193. doi: 10.1053/j.gastro.2004.09. 033.

[75] Sugahara S, Nakayama H, Fukuda K, Mizumoto M, Tokita M, Abei M, et al. Proton-beam therapy for hepatocellular carcinoma associated with portal vein tumor thrombosis. Strahlenther Onkol 2009;185:782-788. doi: 10 . 1007/s00066-009-2020-x.

[76] Kawashima M, Furuse J, Nishio T, Konishi M, Ishii H, Kinoshita T, et al. Phase II study of radiotherapy employing proton beam for hepatocellular carcinoma. J Clin Oncol 2005;23:1839-1846. doi: 10.1200/JCO.2005.00.620.

[77] Yoo GS, Yu JI, Park HC. Proton therapy for hepatocellular carcinoma: Current knowledges and future perspectives. World J Gastroenterol 2018; 24:3090-3100. doi: 10.3748/wjg.v24.i28.3090.

[78] Kato H, Tsujii H, Miyamoto T, Mizoe JE, Kamada T, Tsuji H, et al. Results of the first prospective study of carbon ion radiotherapy for hepatocellular carcinoma with liver cirrhosis. Int J Radiat Oncol Biol Phys 2004;59: 1468-1476. doi: 10.1016/j.ijrobp.2004.01.032.

[79] Komatsu S, Fukumoto T, Demizu Y, Miyawaki D, Terashima K, Sasaki R, et al. Clinical results and risk factors of proton and carbon ion therapy for hepatocellular carcinoma. Cancer 2011;117:4890-4904. doi: 10 . 1002/cncr.26134.

[80] Igaki $H$, Mizumoto $M$, Okumura $T$, Hasegawa $K$, Kokudo $N$, Sakurai $H$. A systematic review of publications on charged particle therapy for hepatocellular carcinoma. Int J Clin Oncol 2018;23:423-433. doi: 10. 1007/s10147-017-1190-2.

[81] Wang EA, Broadwell SR, Bellavia RJ, Stein JP. Selective internal radiation therapy with SIR-Spheres in hepatocellular carcinoma and cholangiocarcinoma. J Gastrointest Oncol 2017;8:266-278. doi: 10.21037/jgo.2016.11. 08.

[82] Riaz A, Lewandowski RJ, Kulik LM, Mulcahy MF, Sato KT, Ryu RK, et al. Complications following radioembolization with yttrium-90 microspheres: a comprehensive literature review. J Vasc Interv Radiol 2009;20:11211130. doi: 10.1016/j.jvir.2009.05.030.

[83] Wright CL, Werner JD, Tran JM, Gates VL, Rikabi AA, Shah MH, et al. Radiation pneumonitis following yttrium-90 radioembolization: case report and literature review. J Vasc Interv Radiol 2012;23:669-674. doi: 10.1016/j. jvir.2012.01.059.

[84] Rim CH, Kim CY, Yang DS, Yoon WS. Comparison of radiation therapy modalities for hepatocellular carcinoma with portal vein thrombosis: A meta-analysis and systematic review. Radiother Oncol 2018;129: 112-122. doi: 10.1016/j.radonc.2017.11.013
[85] Oladeru OT, Miccio JA, Yang J, Xue Y, Ryu S, Stessin AM. Conformal external beam radiation or selective internal radiation therapy-a comparison of treatment outcomes for hepatocellular carcinoma. J Gastrointest Oncol 2016;7:433-440. doi: 10.21037/jgo.2015.10.04.

[86] Rim CH, Yoon WS. Leaflet manual of external beam radiation therapy for hepatocellular carcinoma: a review of the indications, evidences, and clinical trials. Onco Targets Ther 2018;11:2865-2874. doi: 10.2147/OTT.S164651.

[87] Corrigendum to "EASL Clinical Practice Guidelines: Management of hepatocellular carcinoma" [] Hepatol 69 (2018) 182-236]. ] Hepatol 2019;70: 817. doi: 10.1016/j.jhep.2019.01.020.

[88] Heimbach JK, Kulik LM, Finn RS, Sirlin CB, Abecassis MM, Roberts LR, et al. AASLD guidelines for the treatment of hepatocellular carcinoma. Hepatology 2018;67:358-380. doi: 10.1002/hep.29086.

[89] Kudo M, Matsui O, Izumi N, Iijima H, Kadoya M, Imai Y, et al. JSH consensusbased clinical practice guidelines for the management of hepatocellular carcinoma: 2014 update by the liver cancer study group of Japan. Liver Cancer 2014;3:458-468. doi: 10.1159/000343875.

[90] Omata M, Cheng AL, Kokudo N, Kudo M, Lee JM, Jia J, et al. Asia-Pacific clinical practice guidelines on the management of hepatocellular carcinoma: a 2017 update. Hepatol Int 2017;11:317-370. doi: 10.1007/s12072-0179799-9.

[91] 2014 Korean Liver Cancer Study Group-National Cancer Center Korea practice guideline for the management of hepatocellular carcinoma. Korean J Radiol 2015;16:465-522. doi: 10.3348/kjr.2015.16.3.465.

[92] Zhou J, Sun HC, Wang Z, Cong WM, Wang JH, Zeng MS, et al. Guidelines for diagnosis and treatment of primary liver cancer in China (2017 Edition). Liver Cancer 2018;7:235-260. doi: 10.1159/000488035.

[93] Bujold A, Massey CA, Kim JJ, Brierley J, Cho C, Wong RK, et al. Sequential phase I and II trials of stereotactic body radiotherapy for locally advanced hepatocellular carcinoma. J Clin Oncol 2013;31:1631-1639. doi: 10. 1200/JCO.2012.44.1659.

[94] Culleton S, Jiang H, Haddad CR, Kim J, Brierley J, Brade A, et al. Outcomes following definitive stereotactic body radiotherapy for patients with ChildPugh B or C hepatocellular carcinoma. Radiother Oncol 2014;111:412-417. doi: 10.1016/j.radonc.2014.05.002.

[95] Lasley FD, Mannina EM, Johnson CS, Perkins SM, Althouse S, Maluccio M, et al. Treatment variables related to liver toxicity in patients with hepatocellular carcinoma, Child-Pugh class A and B enrolled in a phase 1-2 trial of stereotactic body radiation therapy. Pract Radiat Oncol 2015;5:e443-e449. doi: $10.1016 /$ j.prro.2015.02.007.

[96] Kang JK, Kim MS, Cho CK, Yang KM, Yoo HJ, Kim JH, et al. Stereotactic body radiation therapy for inoperable hepatocellular carcinoma as a local salvage treatment after incomplete transarterial chemoembolization. Cancer 2012 118:5424-5431. doi: 10.1002/cncr.27533.

[97] Sanuki N, Takeda A, Oku Y, Mizuno T, Aoki Y, Eriguchi T, et al. Stereotactic body radiotherapy for small hepatocellular carcinoma: a retrospective outcome analysis in 185 patients. Acta Oncol 2014;53:399-404. doi: 10. 3109/0284186X.2013.820342.

[98] Jang WI, Kim MS, Bae SH, Cho CK, Yoo HJ, Seo YS, et al. High-dose stereotactic body radiotherapy correlates increased local control and overall survival in patients with inoperable hepatocellular carcinoma. Radiat Oncol 2013;8:250. doi: 10.1186/1748-717X-8-250.

[99] Yoon SM, Lim YS, Park MJ, Kim SY, Cho B, Shim JH, et al. Stereotactic body radiation therapy as an alternative treatment for small hepatocellular carcinoma. PLoS One 2013;8:e79854. doi: 10.1371/journal.pone.0079854.

[100] Yamashita H, Onishi H, Murakami N, Matsumoto Y, Matsuo Y, Nomiya T, et al. Survival outcomes after stereotactic body radiotherapy for 79 Japanese patients with hepatocellular carcinoma. J Radiat Res 2015;56:561567. doi: $10.1093 / \mathrm{jrr} /$ rru130.

[101] Hasan S, Thai N, Uemura T, Kudithipudi V, Renz P, Abel S, et al. Hepatocellular carcinoma with child Pugh-A Cirrhosis treated with stereotactic body radiotherapy. World J Gastrointest Surg 2017;9:256-263. doi: 10. 4240/wjgs.v9.i12.256.

[102] Sapir E, Tao Y, Schipper MJ, Bazzi L, Novelli PM, Devlin P, et al. Stereotactic body radiation therapy as an alternative to transarterial chemoembolization for hepatocellular carcinoma. Int J Radiat Oncol Biol Phys 2018;100:122130. doi: $10.1016 /$ j.ijrobp.2017.09.001.

[103] Mohamed M, Katz AW, Tejani MA, Sharma AK, Kashyap R, Noel MS, et al. Comparison of outcomes between SBRT, yttrium-90 radioembolization, transarterial chemoembolization, and radiofrequency ablation as bridge to transplant for hepatocellular carcinoma. Adv Radiat Oncol 2015;1:35-42. doi: 10.1016/j.adro.2015.12.003.

[104] Su TS, Liang P, Liang J, Lu HZ, Jiang HY, Cheng T, et al. Long-term survival analysis of stereotactic ablative radiotherapy versus liver resection for small hepatocellular carcinoma. Int J Radiat Oncol Biol Phys 2017;98: 639-646. doi: 10.1016/j.ijrobp.2017.02.095. 